March - 2007

\title{
Replacing Face-to-Face Tutorials by Synchronous Online Technologies: Challenges and pedagogical implications
}

\author{
Kwok Chi Ng \\ The Open University of Hong Kong, PRC
}

\begin{abstract}
This paper reports on a study which investigates the implementation of a synchronous e-learning system (Interwise) for online tutorials on an information technology related course offered by the Open University of Hong Kong (OUHK). It examines a set of interview data related to students' and tutors' views on the use of the system. Issues concerning students' participation in online tutorials, opportunities for interaction in using the system, and tutors' roles in real-time conferences are discussed. The findings suggest that both the students and tutors are positive about the use of Interwise for online tutorials in general. Some students, however, indicate dissatisfaction with the one-way communication and teacher-control functionalities of the system. The results also indicate that the tutors are concerned about the workload involved in using Interwise in terms of managing the functionalities of the system and the different learning tasks. Implications are then drawn for supporting synchronous online learning both in the OUHK and a wider academic context.
\end{abstract}

Keywords: synchronous e-learning system; interaction; online tutors’ roles

\section{Introduction}

The delivery of distance education is usually supplemented by various forms of technology. Recent and rapid improvements in information and communication technologies and the increasing bandwidth of Internet access have made the use of synchronous solutions for instruction more popular. The nature of interaction and the type of instructor support required by asynchronous and synchronous learning environments differ; and the use of synchronous conferencing techniques has unique benefits in education. First, real-time interaction allows simulation of a real classroom learning situation and immediate interactive clarification of meaning (Steeples, Jones, \& Goodyear, 2002). Salmon (2000) also notes that synchronous conferencing through the Internet offers participants a feeling of immediate contact, motivation, and even some fun, which is especially valuable for distance learners.

As a distance learning institution, the Open University of Hong Kong (OUHK) is very interested in exploring strategies to improve the learner support system. Typically, support services include an element of face-of-face tuition to supplement learner progress with self-instructional material. Students are divided into tutorial groups, and each group is taken care of by a tutor who is a part- 
time staff member of the institution. These sessions are conducted every two to three weeks throughout a semester and are held in weekday evenings or weekends to meet the schedules of working adults. Students' participation in these sessions is optional, but they are strongly encouraged to take part in them to benefit from tutor support and share their perspectives and experiences.

\section{Live e-learning with Interwise}

In the April 2003 presentation, the Interwise system was implemented on a pilot basis as an innovation for providing online tutorials for some information technology (IT) related courses. There are several delivery platforms in Interwise, each serving different communication purposes (for details, visit the Interwise website at: http://www.interwise.com/product/) and the iClass platform was adopted. Students' and tutors' roles in iClass are outlined in Appendix 1.

Compared with text-only synchronous communication technologies, the Interwise system has some strong, value added features. For example, it allows the transmission of video, images, PowerPoint slides, and information exchange on a whiteboard. Also, the audio elements in the system are considered to be very useful features by tutors and students. Instead of typing, students can talk with each other and their tutor, just as in a conventional classroom. This relieves students from intensive writing, "which could be a burden in online communication as good keyboarding skills, language proficiency and plenty of time are pre-conditions" (Robertshaw, 2003, p. 10).

Preliminary studies were carried out with the April 2003 cohort of students and tutors, and they showed user satisfaction with the features of the system in general (Chung, 2004). The present study is a more in-depth investigation to research the associated pedagogical issues and the new challenges this technology presents. The notion of 'pedagogy' is worth clarifying. It covers several interrelated dimensions such as: educational goals and purposes; a view of learning, and the learning and assessment activities required; and the roles and relationships among learners and between the teacher and the learner (Leach \& Moon, 1999). The present research reported here, however, focuses mainly on issues related to interaction opportunities and tutors' roles in synchronous online learning environments.

\section{Theoretical Ideas Underlying the Study}

\section{Interaction in synchronous communication technologies}

Interaction has long been a defining and critical component of the educational process and context and has always been valued in distance education - even in its most traditional, independent study format (Holmberg, 1989). The effectiveness of the interactive learning experience, however, is influenced by a range of diverse and complex factors.

For example, Sims (2003) used a survey instrument to examine perceptions of the relationship between interactivity and learning in the context of online and flexible learning environments. The participants were students $(n=68)$ studying an undergraduate course in multimedia and interactive learning in an Australian regional university. Six themes related to participants' expectations of effective interactive online learning experience - engagement, control, communication, design, the individual and learning - were identified. Sims (2003) argues that "learners taking on a more participatory role" and "creating opportunities that are more adaptable 
to the characteristics and preferences of the individual users" (p. 101) are essential determinants of the success of interactive, computer-enhanced learning environments.

Anderson's (2003) notion of 'equivalency of interaction' adds a useful perspective on the issue of interaction in online learning. It claims that no single medium supports the educational experience in a manner that is superior in all ways to other media. Therefore, "deep and meaningful formal learning is supported as long as one of the three forms of interaction (student-teacher; studentstudent; student-content) is at a high level. The other two may be offered at minimal levels, or even eliminated, without degrading the educational experience" (\$ 10). Anderson (2003) also notes that synchronous technologies, such as audio and video conferencing, provide slightly less interaction between students and among teachers and students due to the inherent technological distance between students and teachers imposed by the mediating technology. Although high levels of student-student interaction are possible in these conferencing systems, there is much anecdotal evidence that teachers often use the media almost exclusively for lecture-type delivery.

Some studies have indicated greater improvements in the level of active participation, the quality of discussion and group dynamics when synchronous collaborative systems are brought into teaching (Marjanovic, 1999). McAlister, Ravenscroft, and Scanlon (2004) also found that their design for synchronous online peer discussion, which included contextual issues, led to improved argumentation and collaborative knowledge development among their UK Open University students. They considered that social relationships, shared understanding, and clear identities were of particular importance in synchronous online interaction.

\section{Tutors' roles in synchronous online teaching}

While there has been extensive research into the role of tutors in facilitating asynchronous online discussion, less attention has been paid to the part they play in synchronous online learning environments. Salmon (2000) considers that "the role of the e-moderator in online synchronous discussion reflects some of the qualities of the asynchronous e-moderator, especially to focus the conference at the beginning, keep it roughly on track and summarize it" (p. 46).

Several studies have been carried out to examine the tutor role/ participation in synchronous online learning environments. For instance, Ligorio Talamo, and Simons (2002) carried out a cross-national project involving a virtual community formed by students, teachers, and researchers from two countries - Italy and the Netherlands - who designed, built, and populated a three-dimensional world. The findings suggested that the tutors had a very significant role in the four functions in chat room activities - namely, managerial, social, technical, and pedagogical.

Also, Burnett (2003) examined tutor participation in synchronous online chat by analysing the chat records. Three areas of tutor responsibility in online chat were identified - social, organizational, and intellectual. The studies by both Ligorio and colleagues (2002) and Burnett (2003) highlight the significance of the social dimension in establishing a supportive atmosphere in synchronous interaction and indicate that the tutor needs to play the role of a facilitator rather than a leader.

e-Moderation of academic discussions presents various challenges. For example, reflecting on his experience in managing online chat activities, Ng (2004) considered that the handling of participants' communication anxiety was a very significant issue. Real-time interaction requires immediate responses, which may make students anxious; and anxiety can also be caused by delays in replying to messages. In-depth clarification of academic issues also seems difficult in 
real-time interaction. Moreover, spontaneous responses can be problematic for some students as the opportunity to participate may be lost if the pace of the discussion moves too quickly.

In summary, the tutor plays a significant role in promoting a meaningful interactive learning experience for students in synchronous online learning environments. Anderson, Fyvie, Koritko, McCarthy, Paz, et al., (2006) suggest that the tutor needs to plan thoroughly for an effective and inclusive synchronous learning experience and pay particular attention to the following problems:

- $\quad$ The online conferencing tool may be new to the tutor and the participants;

- The learning environment may provide multiple tools for communication and presentation, such as text-chat, synchronous presentation, shared whiteboard and cobrowsing;

- There is a short time-frame in which to cover the required material and to solicit active participation; and

- Technical problems may arise during the session, further reducing the time available.

\section{Purposes of the Study}

This study explores the following questions related to the pedagogical issues and challenges Interwise presents:

1. How did the tutors use Interwise for teaching and in what ways did the students participate in online tutorials?

2. What factors can facilitate or hinder the opportunities for interaction and effective teaching in the Interwise system?

3. How did the tutors perceive their roles in online tutorials in comparison with face-to-face tutorial sessions? How did the students perceive the tutors' roles in online tutorials? Did this match their expectations?

4. What were the students' preferences as regards to online tutorials and face-to-face tutorial classes?

\section{Methods}

A case study approach was adopted for the study. In the context of implementing online technologies for teaching and learning, case studies are useful methods for providing insights for planning and staff development purposes, as well as in policy making within institutions (Murphy, Walker \& Webb, 2001).

\section{Selection of the case - U123}

U123 - Introduction to the Internet is a foundation course for students who need to acquire basic practical Internet skills. The course is designed for students with a wide range of experience with the Internet. By selecting this course, the research benefited from the relative stability of the 
course material, as well as the team of tutors already trained and experienced in both supporting the course and using the Interwise system.

The students and tutors in the April 2005 presentation were invited to participate in interviews. There were approximately 200 students in this cohort who were divided into six tutorial groups. The tutorial support included 13 sessions and was offered alternatively in a face-to-face mode (seven sessions) and an online mode (six sessions), with students' participation being voluntary for both modes. At the time of the study, the attendance level in online tutorials was about 50 percent (about 16 students in each tutorial group).

\section{Data collection method}

Six tutors (labelled T1 to T6 in the quotations in the results section) and eight students (S1 to S8) participated in the interviews during September and October 2005. A semi-structured approach was adopted in the interviews and a Research Assistant (RA) conducted them by phone. The interviews were carried out in Cantonese, and were transcribed and translated into English for analysis. The interview questions are provided in Appendix 2.

\section{Interview data analysis}

The tutor and student interview data sets were first handled separately. Interviewees' responses to similar questions were grouped; when the data had been ordered, various themes emerged. The themes which arose from both the students' and tutors' data sets were then compared for triangulation purposes, and were discussed by the author and the RA for conceptual verification. Finally, the data were coded by the author and cross-checked by the RA to ensure the validity and reliability of data interpretation.

\section{Results}

All the students were new to the Interwise system, but the tutors had at least two years' experience using it for online tutorials in either U123 or another course U234 - Website design. In general, students considered that the system was not difficult to use and that the instruction guide was easy to follow. Some reported that they encountered initial hiccups in setting up the system, but the problems were solved by consulting the IT support unit or the tutors. Some also reported confusion in using certain features in the system (e.g., the recording function) at the beginning, but the issues were clarified with the tutors very quickly.

\section{The use of Interwise for teaching}

When asked how they used Interwise for teaching and which of its components they employed most often in conducting online tutorials, the tutors noted that 'lecturing' was the main activity. They considered the 'browser' feature in Interwise (loading webpages on the whiteboard) to be convenient for lecture delivery. All had used the browser for uploading teaching materials or webpages, which they could then explain to students through the audio channel.

Students can ask the tutor questions by sending them text messages (private notes) or through the audio device - with the latter requiring students to have a microphone and permission to speak through the system. The tutors noted the students' preference for sending text messages, which in some cases posed difficulties. For example, one tutor commented that, 
"I may receive several text messages at the same time. While I am typing my answers, there are other messages popping up . . . the biggest problem is there will also be 'dead air' while typing and I cannot talk to students" (T1).

In general, however, most students were not particularly keen on raising discussion questions in online tutorials, so the time allocated for discussion was usually short (roughly about 1/4 of the tutorial time).

Some tutors used the Q\&A features (Yes/ No type questions and multiple-choice questions) in Interwise to monitor students' responses and progress. One tutor considered that such features were useful for gaining students' feedback because,

"All students get an opportunity to answer the questions" (T2).

Another tutor, however, noted that,

"Answering MC type questions can't tell you whether students really understand the course content or not" (T1).

Finally, the tutors rarely used features such as 'application sharing' or 'video show.'

"For U123 . . . little application sharing is needed and I can check students' understanding of the applications through posting MC questions" (T3).

Also,

"[Uploading video in the system] would affect the Internet connection and slow down the data transmission rate" (T4).

\section{Students' participation in online tutorials}

The iClass provides a delivery platform for teachers to upload teaching materials or webpages, which they can then explain to students through the audio channel. Students need to load the learning materials at the start of the session. As noted above, students can ask the tutor questions by sending them text messages (private notes) or through the audio device. In addition, they can record the online session in their computers for revision purposes. In the interviews, the students did not describe their forms of participation in online tutorials in a systematic way. The following are some snapshots:

\section{Preparation and testing systems before class}

"I usually read the learning materials before class, and then I make notes for myself. About 30 minutes before the iClass commences, I test all the peripheral devices (such as mic and speakers, computer ... .), just to make sure everything works and is ready for the lesson" (S1).

Jotting notes, searching for information and recording lessons, 
Kwok Chi Ng

"I jot down notes during class but sometimes I might miss out something if the tutor goes too fast. So I record the lessons to ensure that I have access to the course content at a later time ... I noticed that the tutor doesn't really follow the course materials strictly and I don't always have the notes. So I need to search for the exact references while he gives his lectures" (S2).

Asking the tutor questions by text messages or through the microphone,

"I do ask many questions . . . mostly by text, as I don't want the background sounds from my side to disturb the class" (S2).

"[Prefers asking questions via the mic] . . . it reaches the ears of the tutors directly. With text, I might not be able to convey my messages accurately. It is also faster and other classmates can hear it too . . ." (S5).

\section{Teaching effectiveness and the opportunities for interaction in using Interwise}

The tutors considered that the system has several advantages for the organization of online tutorials. Overall, it was not felt to be difficult to use the Interwise system for teaching as U123 is IT-related and designed for beginners, and online tutorials can supplement the face-to-face sessions. As one tutor pointed out,

"When there isn't enough time for discussion at the end of face-to-face tutorials, students raise the issues in online tutorials . . . in a way, they tend to participate more during online tutorials' (T2).

The lack of a physical presence in online tutorials can also meet the learning needs of some students. As another tutor observed,

"Some students don't seem to respond to questions raised by their classmates during face-to-face tutorials. But sometimes they respond through Interwise. The absence of physical presence seems to relax them" (T5).

There were also challenges, however, in using Interwise for teaching. Technical difficulties can affect the smooth organization of online tutorials. For instance, students encounter problems from time to time with downloading learning materials, a slow network transmission and poor audio effects.

"The stability of the Internet connection and transmission should be improved as well ... sometimes it takes time for students to load up the same webpages. It is very much related to the bandwidth" (T2).

A more significant issue is that the iClass system provides limited interaction opportunities for students in the online learning environment. Some tutors pointed out the limitations of such a design - for example, 
"It works on a one-to-one communication format . . . it tends to encourage discussion between the tutor and an individual student rather than group discussion" (T2).

Also,

"The chat information (private messages sent by students to the tutor) cannot be shared with all students in the class. I have come across situations where the same questions are sent to me by different students" (T1).

The above tutors clearly felt that the provision of more opportunities for interaction would enhance the teaching effectiveness of online tutorials, as this would allow students to initiate discussion topics or lead discussion in tutorials.

\section{Opportunities for interaction in Interwise as perceived by the students}

Overall, the students considered that the student-tutor interaction opportunities in Interwise were adequate. However, they felt that the student-student interaction was extremely limited, for the following reasons.

First, not knowing one's classmates makes communication difficult. Some students indicated that they did not have friends in the class (S4) and classmates were "mostly strangers" (S1). The different learning pace of individual students also makes it difficult to share understanding of course material. One student added,

"Many classmates have not prepared well and have little understanding of course content . . . so I lacked the motivation to communicate more with them . . . "(S1).

Such comments appear to suggest that the social aspect could be a major factor affecting studentstudent interaction in online learning. Not knowing each other, and without a social support network, student-student communication is difficult.

One student also showed dissatisfaction with the functionalities of the system, which hindered better student-teacher interaction:

"I am not entirely comfortable with having to wait till the tutor finishes all his talk through the Internet before we can raise our questions . . . "(S8).

Finally, some expressed dissatisfaction with the one-way communication feature of iClass, as illustrated in the following comment:

"Right now it is only a one-to-one channel. You ask a question and wait for the reply from the tutor, but you cannot chat in real time. Other students cannot join in or show their responses easily ... I think maybe communication can be improved further ... not just waiting till you get the right to speak" (S6). 


\section{Tutors' roles in online teaching}

When asked how they perceived their teaching roles in online tutorials in comparison with faceto-face sessions, all tutors considered online tutorial work to be more demanding. It took them more time to prepare the material for an online tutorial session:

"In addition to the text notes, I have to prepare graphic images and charts as well. Students, therefore, have more questions about the teaching materials which means that I have to prepare more explanatory notes" (T4).

They also need to handle different teaching tasks skillfully in online tutorials. For example, one tutor advised:

"We need to handle different components, tools and programs [in the Interwise system]. We need to focus on lecturing, but when students send in their questions by text, I have to answer them one by one. It takes time" (T6).

Apart from workload issues, the roles tutors need to perform in a virtual learning environment are somewhat different from in face-to-face classes. Several tutors mentioned that they needed to make a greater effort to monitor students' learning progress in online tutorials. They noted that face-to-face tutorials allow observation of students' responses through facial expression and collecting their feedback instantly (T1, T2, T4). With Interwise, however,

"It is difficult to tell whether students fully understand what you are teaching" (T4) and "it depends on the actions of the students, for instance their replies to the MC-type questions" (T2).

\section{Students' perceptions/ expectations of the tutors' roles in online teaching}

In general, students considered that their tutors used the Interwise effectively for teaching and responded to their questions promptly. They commended their tutors for: being well prepared for online tutorials (S6); answering students' questions promptly (S2); and monitoring students' learning processes effectively by sending in MC questions to collect feedback (S7). For instance, the following student praised their tutor's effective control of timing in online tutorials, which is very important in managing synchronous online communication:

"He doesn't linger on for too long. If some demonstration doesn't show, he tells us to wait till the next face-to-face session. There was a time when the connection was off for 15 minutes. The tutor could quickly pick up when the iClass was reconnected ... the class only overran by 5 minutes or so" (S3).

The students, however, also observed that the tutors have to perform somewhat challenging roles in managing online tutorials and handling different teaching tasks skillfully. They made several suggestions to their tutors for improving the effectiveness of online teaching. One student, for example, considered that the tutor could have utilized the features in the system more fully to facilitate teaching: in addition to using the PowerPoint/ whiteboard,

"He could have given more live examples (in the web) so that we can immediately access them" (S1). 
The fact that real-time interaction requires immediate responses presents difficulties for some students in discussing course content in Interwise. In this regard, they wished more time to think about questions and discuss them, as is illustrated by the following comment:

"He does ask us questions in every session. But during online tutorials, things keep 'flowing,' so it takes time to digest. Before we can understand more about the content, the tutor is already onto the next topic . . He is giving a very comprehensive account of the content but that leaves us little time for in-depth discussion" (S5).

Finally, the issue of time management in online tutorials stood out again. For example, 'dead air' can easily occur if the tutor does not handle the Q\&A function skillfully and delays are then caused by tutor's waiting for class feedback (S4). Interruptions to online classes can also result from the malfunctioning of students' microphones or speakers during the tutorials and late attendants logging into the system (S5). These comments again highlight the fact that moderation work in online tutorials can be very demanding, with important tutor workload implications.

\section{Online tutorials vs. face-to-face classes}

Students were asked to compare their learning experience in online tutorials and face-to-face classes and indicate their preferred mode. The issue of interaction was highlighted again. Not surprisingly, the students indicated clearly that face-to face classes promoted better interaction and more accurate communication. They noted that instant responses are important for communication and the responses are more spontaneous in face-to-face meetings (S3, S4, S5, S6 and S7), as is illustrated in the following comment:

"First, it's about interpretation. Some words cannot be taken at face value through the Internet . . . Maybe it's my own perception . . . but with eye contact; confirmation can be made ... more accurate" (S5).

Interestingly, except in one case (S5), the respondents also expressed the view that the convenience of online tutorials outweighed the better interaction in face-to-face tutorials. The following comment gives some reasons for such a claim:

"I find it easier to communicate with other students face-to-face, and see their instant responses ... I personally prefer online tutorials, as I live quite far away so I don't need to travel to a specific location to attend the class. There are factors such as my full-time job, my children ... et cetera. It is more convenient to use Interwise" (S6).

Apart from convenience in time and place, some students highlighted other advantages of online tutorials such as: ease in asking questions 'behind the veils' and the fact that questions can be 'better shaped' (S2). They noted that they can record the tutorials for revision, and learn from other tutors who have different focuses (S5, S7). Also the online tutorial mode may suit the study of computer-related courses like U123.

"For U123, if we attend face-to-face tutorials, we don't have the computers in class. But with Interwise, I can use three computers at home at the same timeone computer to view the tutors' materials, and others to search for the related 
materials on the net and do the recording . . . iClass offers more convenience and enhanced usage of the computer" (S1).

Finally, one student noted that a combination of face-to-face and online tutorials is important.

"Both modes have their own advantages. Some students are more passive in learning. Online tutorials allow us to follow the tutor's instructions and try things out ... Even if issues are not as clear in online tutorials, the problems can be addressed quickly in the following face-to-face tutorials . . . Using Interwise (online tutorials) to cover the whole course without face-to-face teaching is not exactly what I would prefer" (S3).

\section{Discussion and Conclusions}

This research has helped to increase our understanding of the pedagogical implications of replacing face-to-face tutorial sessions with online tutorials, and of the challenges in managing real-time conferences for learning. It also highlights some possible areas for further exploration of the opportunities provided by the new technology.

\section{The opportunities for interaction in using Interwise}

An important issue in online delivery is whether it can provide an interactive learning environment for the participants. The findings in this study indicated that the students and tutors were concerned about the limited interaction opportunities provided by the technology. Several students indicated dissatisfaction with the one-way communication and teacher-control functionalities of iClass; and some tutors also mentioned that the platform might hinder students' participation and their playing a more active role in learning. Both students and tutors, however, were positive about the use of Interwise for online tutorials in general. They considered that, as a supplement to face-to-face tutorials, the provision of online tutorials can further meet students' learning needs and had enhanced their study of the course concerned.

The concept of 'equivalency of interaction' (Anderson, 2003) can help to explain their reaction to using iClass for teaching and learning. This platform is basically a teacher-led learning environment which is not designed for student-student interaction. The data indicated that 'student-teacher' interaction and 'student-content' interaction were supported by the system, but 'student-student' interaction was achieved at only a very minimal level. Clearly, increasing the learner interaction opportunities has significant pedagogical implications - for example, by including collaborative learning tasks. Other elements in Interwise - for instance, the iMeeting platform - might provide a more interactive learning environment for learners, and its effectiveness in distance education would be worth further examination.

\section{The tutors' roles in online teaching}

Facilitating learning in real time involves complex and demanding tasks (Finkelstein, 2006). The tutors in this study encountered difficulties in managing synchronous online learning, an issue mentioned also by Anderson and colleagues (2006). Their comments highlighted the heavy demands of working in online tutorials in terms of managing the multiple tools for communication and presentation. Also, it took them more time to prepare the material for online tutorial sessions and they needed to make a greater effort to monitor students' learning progress. 
The issue of tutors' workload and the related stress in synchronous online interaction needs to be addressed for more effective use of the system - for instance, by reducing class size or promoting/ sharing good practices. Further investigation of tutors' roles and the supporting mechanisms for online teaching is also needed.

\section{The social dimensions of learning}

As noted in the literature review, establishing a social network and supportive atmosphere are critical for motivating participants to play an active role in synchronous interaction (Burnett, 2003). Finkelstein (2006) also notes that socialization and informal exchanges are very important for the learning process in synchronous online learning environments, as "they help build community and create a friendly and safe environment in which people can feel like people" (p. 4).

The data in this research suggested that social relationships were not developed among this group of students, which may have hindered their interaction. Students may feel uncomfortable in expressing their views and sharing their perspectives when they do not know each other. Encouraging students to participate in face-to-face sessions can help them to develop social support networks for learning. It is interesting that some students expressed the view that a combination of online and face-to-face sessions is important for learning. The optimum mix of these two modes of learner support and the best strategies for enhancing the social dimensions of learning in an online environment are issues worth further study.

\section{Technical problems in using the new technology}

Finally, the technical challenges of using the new learning tools should not be overlooked. Although the participants in this study had an IT background and considered that the system was not difficult to use, some interruptions of online classes did occur because of malfunctioning of the devices. Strengthening the provision of technical guidance/ support and reminding students to prepare and test systems before class can enhance their experience and facilitate the smooth operation of online tutorials.

In conclusion, real-time online instructional tools hold great promise for supporting student learning in distance education. The unique potential of synchronous instruction and communication online, however, must be recognized if the tools are to be used effectively and make a real difference to learner outcomes.

\section{Acknowledgement}

The research was supported by grants from the President's Advisory Committee on Research and Development of the Open University of Hong Kong. Michael Robertshaw and Linda H. M. Chung were members of the project team. I would also like to thank Sanna Lee for collecting and transcribing the data. 


\section{References}

Anderson, T. (2003). Getting the Mix Right Again: An updated and theoretical rationale for interaction. International Review of Research in Open and Distance Learning, 4(2). Retrieved April 6, 2006 from: http://www.irrodl.org/index.php/irrodl/article/view/149/230

Anderson, L., Fyvie, B., Koritko, B., McCarthy, K., Paz, S. M., Rizzuto, M., Tremblay, R. and Sawyers, U. (2006). Best Practices in Synchronous Conferencing Moderation. Technical Evaluation Report. International Review of Research in Open and Distance Learning, 7(1). Retrieved June 30, 2006 from: http://www.irrodl.org/index.php/irrodl/article/view/308/483.

Burnett, C. (2003). Learning to Chat: Tutor participation in synchronous online chat. Teaching in Higher Education, 8(2), 247-261.

Chung, L. H. M. (2004). Evaluation report on the use of Interwise - CT212 and U123 April 2003 presentation. OUHK internal report: Open University of Hong Kong.

Finkelstein, J. (2006). Learning in Real Time: Synchronous teaching and learning online. San Francisco: Jossey-Bass.

Holmberg, B. (1989). Theory and practice of distance education. London: Routledge.

Leach, J., \& Moon, R. (1999). Recreating pedagogy. In J. Leach \& R. Moon (Eds) Learners and Pedagogy. London: Paul Chapman.

Ligorio, M. B., Talamo, A., \& Simons, R. (2002). Synchronic tutoring of a virtual community. Mentoring and Tutoring, 10(2), 137-152.

Marjanovic, O. (1999). Learning and teaching in a synchronous collaborative environment. Journal of Computer Assisted Learning, 15(2), 129-138.

McAlister, S., Ravenscroft, A., \& Scanlon, E. (2004). Combining interaction and context design to support collaborative argumentation using a tool for synchronous CMC. Journal of Computer Assisted Learning, 20, 194-204.

Murphy, D., Walker, R., \& Webb, G. (Eds.) (2001). Online Learning and Teaching with Technology: Case studies, experience and practice. London: Kogan Page.

Ng, K. C. (2004). Challenges in implementing chat room activities in a distance education course. Paper presented at the 21st ICDE World Conference, February 14-18. Hong Kong, PRC.

Robertshaw, M. (2003). New technology adds flexibility to online tutorials (an interview script). Openlink, 12(4), 10.

Salmon, G. (2000). E-moderating: The key to teaching and learning online. London: Kogan Page. 
Sims, R. (2003). Promises of Interactivity: Aligning learner perceptions and expectations with strategies for flexible and online learning. Distance Education, 24(1), 87-104.

Steeples, C., Jones, C., \& Goodyear, P. (2002). Beyond e-Learning: A future for networked learning. In C. Steeples \& C. Jones (Eds.) Networked Learning: Perspectives and issues. London: Springer-Verlag.

\section{Appendix 1 Tutors' and students' roles in iClass}

\section{Tutors' roles in iClass}

1. Define the details of iClass, such as scheduling the classes.

2. Establish voice and video control.

3. Work with the pointer and graphic tools.

4. Load materials/ webpages for students.

5. Share an application.

6. Communicate with students using text notes.

7. Send questions to students and monitor their responses.

\section{Students' roles in iClass}

1. View whatever the tutor is doing on screen.

2. Converse and exchange text notes with the tutor/other students.

3. Perform whiteboard operations while speaking.

4. Share an application with the tutor.

5. Answer questions posed by the tutor.

\section{Appendix 2 Interview schedules for students and tutors}

\section{The interview schedule for students}

1. Are you familiar with using synchronous online communication systems?

2. Did you participate in any online tutorial sessions for U123? Why/ why not? (For nonparticipants, please provide us with more information about why you did not participate and skip the next question.)

3. Please describe the forms of your participation in online tutorials. For example, did you often 
ask the tutor questions and respond to his/ her questions? Did you interact with other students when they raised problems and send them private notes?

4. What was your general impression of participating in online tutorial sessions? What was good about using the online tutorial system (Interwise)? What was not good about using it?

5. Have you encountered any problems (e.g., technical, social, cultural) when participating in online tutorials? If so, what were they, and how did you try to solve them?

6. How would you compare your learning experience in online and face-to-face tutorials? Do you think the participation in online tutorials has helped your study of the course?

7. Have you any suggestions for improving the organization of online tutorials in the future?

\section{The interview schedule for tutors}

1. How did you use the Interwise system for teaching? Which components did you use most often? Why?

2. How would you compare your experience in managing the online tutorial groups and the faceto-face sessions?

3. What is your general impression of using the Interwise system for teaching? What was good about using it? What was not good about using it?

4. Have you encountered any problems (e.g., technical, social, cultural) when conducting online tutorials? If so, what were they and how did you try to solve them?

5. How do you perceive your teaching role in online tutorials? Has the use of an online tutorial system changed your mode of teaching?

6. Do you think the organization of online tutorials has facilitated students' study of U123? Why/ why not?

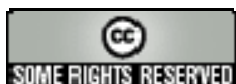

